\title{
A comparative account of biogenic synthesis of silver nanoparticles using in-house potential probiotics and their antimicrobial activity against challenging antibiotic resistant pathogens
}

SHAKSHI SHARMA ( $\square$ shakshi.sharma2193@gmail.com)

Dr Yashwant Singh Parmar University of Horticulture and Forestry https://orcid.org/0000-0002-16690873

\section{NIVEDITA SHARMA}

Dr Yashwant Singh Parmar University of Horticulture and Forestry NEHA KAUSHAL

Dr Yashwant Singh Parmar University of Horticulture and Forestry

\section{Research Article}

Keywords: silver nanoparticles, AgNP, probiotics, Lactobacillus, antibacterial, TEM, FTIR

Posted Date: August 13th, 2021

DOl: https://doi.org/10.21203/rs.3.rs-806048/v1

License: (c) (1) This work is licensed under a Creative Commons Attribution 4.0 International License.

Read Full License 


\section{Abstract}

The present work focusses on development of a safe, inexpensive, and more accessible source for biosynthesis of silver nanoparticles. Four different in-house probiotic isolates i.e., Lactobacillus pentosus S6, Lactobacillus plantarum F22, Lactobacillus crustorum F11 and Lactobacillus paraplantarum KM1 isolated from different food sources, were used in the current study to check their ability to synthesize silver nanoparticles. All the probiotics synthesized silver nanoparticles shows maximum Surface Plasmon Resonance (SPR) at a peak of $450 \mathrm{~nm}$, which confirms the formation of silver nanoparticles. Scanning Electron Microscopy (SEM) analysis identified the shape and distribution of silver nanoparticles. Transmission Electron Microscopy (TEM) revealed the average size of synthesized nanoparticles in the range of 10-50 nm, with smallest size of $5 \mathrm{~nm}$ for silver nanoparticles synthesized by L. crustorum F11. Further, Fourier-transform infrared spectroscopy (FTIR) detected the presence of different functional groups responsible for reduction of silver ion to form silver nanoparticles. The antimicrobial activity of these AgNP was also found to be effective against different bacterial and fungal pathogens viz. antibiotic resistant Staphylococcus aureus, Bacillus cereus, Listeria monocytogenes , Pythium aphanidermatum , Fusarium oxysporum and Phytopthora parasitica . However, L.crustorum F11 synthesized AgNP showed maximum inhibition against all the bacterial and fungal pathogens, with highest against $\mathrm{S}$. aureus $(200.61 \mathrm{~mm})$ and F. oxysporum (23). Findings from this study provide a durable and ecofriendly method for the biosynthesis of silver nanoparticles, having strong antimicrobial activity against different multidrug resistant microorganisms.

\section{Introduction}

Nanotechnology is a rapidly evolving field of science, that has been flourishing since the beginning of last century. It involves the synthesis of particles at nanoscale level having size less than $100 \mathrm{~nm}$ (Arshad, 2017). There is an increase concern worldwide about the rise in antibiotic resistant cases, as harmful pathogenic microorganisms have developed resistance against already used different antibiotics (Khatoon et al. 2019). These multidrug- resistant organisms (MDROs) are multiplying at faster rate, making various health related infections almost untreatable (Lee et al. 2019; Boucher et al. 2009; Peleg and Hooper, 2010). Therefore, nanotechnology is coming forward with a solution to treat these infections as studies revealed that the utilization of nanoparticles provides a potential to manage infection caused by these pathogenic microorganisms (Baptista et al., 2018; Muzammil et al. 2018). Among metallic nanoparticles, silver and gold nanoparticles are most promising nanoparticles because of their large surface area to volume ratio, which has garnered interest in the researchers due to the growing microbial resistance against metal ions, antibiotics and the development of resistant strains (Mosallam et al. 2014). Silver nanoparticles (AgNPs) are gaining attention as one of the most promising nanoparticles due to its unique properties (Yusof et al. 2020). AgNPs have strong toxic effect against wide range of microorganisms and can be used as a potential antimicrobial agent (Naseer et al. 2020). There are different physical and chemical methods already being used for the synthesis of nanoparticles, since these are associated with hazardous chemicals exhibiting toxicity (Hemlata et al. 2020), biologically 
synthesized metallic nanoparticles are preferred for their ecofriendly nature, cost effectiveness and less hazardous effect.

Probiotics are the live microbes that exert health beneficiary effects to the host cell, when administrated in an adequate amount (Pandey et al. 2010). The utilization of probiotic bacteria to synthesize nanoparticles has been reported in different studies and is a focus of ongoing research nowadays (Akhtar and Pathak, 2017). Probiotics are now being employed in synthesizing or more precisely biosynthesizing various nanoparticles, such as metallic as well as non-metallic nanoparticles. Probiotics synthesized nanoparticles has its application in health industry, food industry, cosmetics and biotechnology. The bacterial genera Lactobacillus and Bifidobacterium are the most widely used probiotics, that are being used in biosynthesis of silver nanoparticles. These probiotic synthesized silver nanoparticles have been found to possess effective antimicrobial efficacy against a wide range of pathogenic microbes and have enhanced surface area to volume ratio, high catalytic capabilities and tendency to generate reactive oxygen species (Berton et al. 2014). Thus these Probiotics synthesized nanoparticles can be employed as an alternative of antibiotic as they have the ability to inhibit harmful microorganisms present in human body (Hong et al. 2019; Gillor et al. 2008).

As the use of probiotics in synthesizing nanoparticles is a novel and current trending research due to multiple benefits of probiotics, in the present paper an attempt has been made to synthesize silver nanoparticles from four in-house potential probiotic cultures i.e. Lactobacillus pentosus S6, Lactobacillus plantarum F22, Lactobacillus crustorum F11 and Lactobacillus paraplantarum KM1 that have already been isolated from different food sources and their characterization by using UV-Visible spectroscopy, Scanning Electron Microscopy (SEM), Transmission Electron Microscopy (TEM) and Fourier Transform Infrared Spectroscopy (FTIR). Further their antagonistic spectrum was examined against different challenging pathogens (Bacteria and Fungi).

\section{Materials And Methods}

\section{Materials}

The four in-house potential probiotic cultures isolated from different food sources were collected from Microbiology laboratory, Department of Basic Sciences, UHF Nauni, Solan, H.P, India, for the biosynthesis of silver nanoparticles and analysis of their antimicrobial potential. Table 1 shows the different in-house cultures collected for the study. All the probiotic isolates were cultivated in de Man, Rogosa and Sharpe (MRS) broth separately for $24 \mathrm{~h}\left(37^{\circ} \mathrm{C}\right)$. The bacterial strains used in the study were obtained from MTCC (IMTECH, Chandigarh), CRI (Kasauli) and IGMC (Shimla). All the chemicals used in this study were of analytical grade. 
Table 1

list of in-house potential probiotic cultures collected for synthesis of silver nanoparticles

\begin{tabular}{|lll|}
\hline Name & Accession number & Food Source \\
\hline Lactobacillus pentosus S6 & KU92122 & Siddu \\
\hline Lactobacillus plantarum F22, & KT865223 & Chhang \\
\hline Lactobacillus crustorum F11 & KT865221 & Human milk \\
\hline Lactobacillus paraplantarum KM1 & KX671558 & Milk \\
\hline Source: Microbiology research laboratory, Deptt. Of Basic Sciences, UHF Nauni, Solan, H.P, India \\
\hline
\end{tabular}

\section{Biosynthesis of silver nanoparticles using probiotic isolates}

The collected probiotic strains were inoculated in $100 \mathrm{ml}$ of MRS media and was incubated overnight at $37^{\circ} \mathrm{C}$ for $24 \mathrm{~h}$. After incubation, the culture was centrifuged at 10,000 rpm for $15 \mathrm{~min} .10 \mathrm{ml}$ of culture supernatant from each isolate was separately mixed with 90 silver nitrate $\left(\mathrm{AgNO}_{3}\right)$ solution $(0.1 \mathrm{mM})$ and another reaction mixture without silver nitrate was used as control. The prepared solutions were incubated at $30^{\circ} \mathrm{C}(24 \mathrm{~h})$ and kept in dark to avoid any photochemical reactions during the investigation. The change in color in synthesized silver nanoparticles was observed after $24 \mathrm{~h}$. The biosynthesized silver nanoparticles were then characterized by using UV-vis, SEM, TEM and FTIR spectroscopy.

\section{Characterization of silver nanoparticles}

\section{UV-Visible Spectroscopy Analysis}

Silver nanoparticles were analyzed by UV-Vis spectrophotometer (Shimadzu 1600, Japan). The bio reduction of silver ion in aqueous solution was monitored by periodic diluted sampling of aliquots and subsequently measuring the spectra of the solution on UV-Vis spectrophotometer (Sarvamangla et al. 2013). The absorbance of all the four synthesized silver nanoparticle was read at different wavelengths i.e., $350,450,550$ and $650 \mathrm{~nm}$.

\section{Scanning electron microscopy (SEM)}

The thin film of the different probiotic synthesized nanoparticles was prepared separately on aluminum plate by just dropping a very small amount of the sample on the plate, extra solution was removed using blotting paper and then the film on the plate was allowed to dry overnight. The SEM analysis was performed on a JEOL; model JSM - 6610LV instrument operated at an accelerating voltage of 20 $\mathrm{KeV}$ (Sarvamangla et al. 2013).

\section{Transmission electron microscopy (TEM)}

Transmission Electron Microscopy was performed by using model FP 5022/22-Tecnai G2 20 S-TWIN. TEM shows the size, shape, appearance and crystal structure of the particles. The grid for TEM analysis 
was prepared by placing a drop of the synthesized nanoparticles suspension on a carbon-coated copper grid and allowing the water to evaporate inside a vacuum dryer for $1 \mathrm{~h}$.

\section{Fourier transform infrared spectroscopy (FTIR)}

The synthesized silver nanoparticles were further characterized by their FTIR analysis. The small amount of synthesized silver nanoparticles was dried in freeze-drier separately (Lyophilizer) for $24 \mathrm{~h}$, then freeze dried sample was appointed with $\mathrm{KBr}$ pellets and analyzed using a Thermo Nicolet model: nexus 870 in range of $450-4000 \mathrm{~cm}^{-1}$ at a resolution of $4 \mathrm{~cm}^{-1}$ (Omidi et al. 2014)

\section{Antibacterial efficacy of silver nanoparticles}

Antibacterial assay of synthesized silver nanoparticles was performed against three standard test indicators i.e., antibiotic resistant Staphylococcus aureus IGMC, Listeria monocytogenes MTCC839 and Bacillus cereus CRI using well plate assay (Kimura et al. The inoculum of each pathogen was grown in nutrient broth overnight $\left(37^{0} \mathrm{C}\right)$. Each pathogen was streaked on a separate nutrient agar plate using

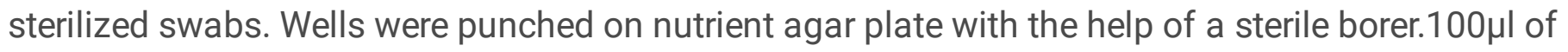
biosynthesized silver nanoparticles (concentration: $200 \mu \mathrm{g} / \mathrm{ml}$ ) from all the four different probiotic isolates was added to each well cut on the agar plate separately. The experiment was performed in triplicates.

\section{Antifungal activity of silver nanoparticles}

Antifungal activity was checked against three fungal pathogens viz. Pythium aphanidermatum, Fusarium oxysporum and Phytopthora parasitica by well plate assay using dual culture technique (Mew and Rosales, 1984). On the one side of prepoured sterilized potato dextrose agar (PDA) plates, 7 days old culture bit of indicator fungi was placed with the help of sterile well borer and inoculating loop. On the other side of PDA plate, well was cut with the help of sterile borer followed by addition of $100 \mu \mathrm{l}$ of 0.1 $\mathrm{mM}$ probiotics synthesized AgNP were added to the well. Plates were incubated at $28 \pm 2^{\circ} \mathrm{C}$ for 7 days and observed for inhibition of mycelial growth produced around the well. The experiment was performed in triplicates.

\section{Results And Discussion}

The utilization of microorganisms for the biosynthesis of nanoparticles, has gained considerable attention in the recent times as compared to the previously used standard methods. This work reports the biosynthesis of AgNPs using four different in-house potential probiotic strain i.e., Lactobacillus pentosus S6 and Lactobacillus plantarum F22, Lactobacillus crustorum F11 and Lactobacillus paraplantarum $\mathrm{KM} 1$, to check their ability to synthesize them and determination of their antimicrobial activity.

\section{Biosynthesis of silver nanoparticles}


Silver nitrate was used as a precursor for the biosynthesis of silver nanoparticles. The first distinctive feature of the formation of silver nanoparticles is the color change in the solution after 24 hours of incubation. Silver nitrate was colorless and after reduction by probiotic isolates, the supernatant changed into brown color. All the four probiotic isolates were capable of synthesizing silver nanoparticles as all of them showed color change after incubation as compared to control $\left(\mathrm{AgNO}_{3}\right)$ (Fig. 1 a). The severity of color is due to actuated surface Plasmon vibration in the metal nanoparticles (Prasad et al. 2011). Different microorganisms have different mechanisms of synthesizing nanoparticles. However, nanoparticles are usually formed when microbial cells trapped metal ions on the surface or inside, and then trapped metal ions are reduced to nanoparticles in the presence of enzymes (Xiangqian et al. 2011). Several studies have reported the synthesis of silver nanoparticles using different microorganisms, but much work is needed to be done to improve their efficacy, maintaining their particle size and future safety concerns. Thus, in the present study an attempt has been made to check the ability of different in-house probiotic microorganisms that are isolated from different food sources to synthesize silver nanoparticles. Over the last few decades, there has been growing interest in the use of probiotics as potential alternatives for synthetic antibiotics and anti-inflammatory drugs, not only due to the side effects of synthetic drugs but also to the improper use of antibiotics promotes the development of antibiotic-resistant bacteria. Mikiciuk et al. (2016) depicted the influence of silver nanoparticles on probiotic bacteria. Probiotic bacteria like Bifidobacterium animalis subspecies lactis BB-12, Lactobacillus acidophilus LA-5, and Streptococcus thermophilus ST-Y31 have been taken from fermented milk products to synthesize silver nanoparticles. Ysouf et al. (2020) reported the utilization of biomass of Lactobacillus plantarum TA4 for the biosynthesis of silver nanoparticles.

\section{UV-Visible spectroscopy}

The UV-Vis spectroscopy analysis was the second characterization method used for the confirmation of the synthesis of silver nanoparticles. The process of reaction between the metal ions and biosynthesized silver nanoparticles was monitored using UV spectra through the aqueous solution. The presence of nanoparticles synthesized by Lactobacillus pentosus S6, Lactobacillus plantarum F22, Lactobacillus crustorum $\mathrm{F} 11$ and Lactobacillus paraplantarum KM1 was confirmed by obtaining a spectrum in different wavelength range i.e., 350, 450, 550 and 650nm respectively (Fig 1 b). The highest absorbance peak for all of the four isolates was found at the wavelength of $450 \mathrm{~nm}$, which was specific for silver nanoparticles synthesis. Dhoondia and Chakraborty (2012) observed the maximum absorption peak at $430 \mathrm{~nm}$ for silver nanoparticles synthesized using Lactobacillus mindensis. Malathi et al. (2015) monitored the synthesis of silver nanoparticles from Lactobacillus by UV-spectroscopic analysis. The peak was observed between $400-450 \mathrm{~nm}$ indicating the presence of silver nanoparticles.

\section{Scanning Electron Microscopy (SEM)}

The synthesized silver nanoparticles were further characterized by Scanning Electron Microscopy (SEM). SEM reveals the external morphology and texture of silver nanoparticles. Fig 2 ( $a, b, c$ and d) depicts the SEM analysis of silver nanoparticles synthesized from different probiotics. From the SEM analysis, it can 
be observed that silver nanoparticles from all the four probiotic isolates were spherical in shape and were found as an individual particle and also present in aggregates. Tayo and Papoola (2017) reported that SEM is an important tool for AgNP characterization. Production of silver nanoparticles from Lactobacillus sp. with varying shape i.e., rectangular to spherical was observed (Prabhu et al. 2014). Arshad A (2017) examined SEM analysis of silver nanoparticles synthesized from Bacillus sp, are spherical and pseudo-spherical in shape.

\section{Transmission Electron Microscopy (TEM)}

Transmission Electron Microscopy (TEM) is a valuable tool used to visualize size of synthesized silver nanoparticles. Fig 3 ( $a, b, c$ and d) and Table 2 depicts the TEM images of silver nanoparticles synthesized from L. pentosus S6, L. plantarum F22, L. crustorum F11 and L. paraplantarum KM1 respectively. Silver nanoparticles of different size were synthesized by all the four isolates. L. pentosus $S 6$ synthesized silver nanoparticle has a mean size of $50 \mathrm{~nm}$, whereas, for silver nanoparticle synthesized from L. plantarum F22 it is $20 \mathrm{~nm}$. AgNP from L. plantarum F22 has a size of $10 \mathrm{~nm}$ and for $L$. paraplantarum KM1 it is $50 \mathrm{~nm}$. The silver nanoparticles synthesized in this work were in the same approximate range as reported by other authors for silver nanoparticles synthesized from lactic acid bacteria and other microorganisms (Sintubin et al. 2009; Kalimathu et al. 2008). However, out of all the four probiotics synthesized silver nanoparticles, one synthesized using $L$. crustorum F11 was found to be smaller $(10 \mathrm{~nm})$ of all. Size plays an essential role in nanoparticles applications; smaller particles have a relatively large surface area as compared to larger ones; this increases their interaction with harmful pathogens and consequently trigger more toxic and adverse effect. Many researchers also observed the almost same range of silver nanoparticles synthesized using probiotics just like our findings. Garmasheva et al. (2016) reported the TEM analysis of silver nanoparticles synthesized from lactic acid bacteria and found that the size of nanoparticles was between 10 and $40 \mathrm{~nm}$. Prabhu et al. (2014) also observed the size of silver nanoparticles synthesized by Lactobacillus sp. and found the average size of about 20-40 nm. Ranganath et al. (2012) observed the TEM picture of the silver nanoparticles formed by Lactobacillus sp. VRS-2. The TEM Technique used to visualize size and shapes of biosynthesized silver nanoparticles have predominantly shown spherical shape structures with size ranging between $2 \mathrm{~nm}-20 \mathrm{~nm}$ and have shown the presence of individual as well as number of aggregates of silver nanoparticles.

\section{Table 2: Transmission Electron Microscopy (TEM) analysis of synthesized nanoparticles by different probiotics}




\section{Size of synthesized nanoparticles $(\mathrm{nm})$}

\section{Probiotic culture}

\begin{tabular}{|ll|}
\hline Lactobacillus pentosus S6 & 50 \\
\hline Lactobacillus plantarum F22 & 20 \\
\hline Lactobacillus crustorum F11 & 10 \\
\hline Lactobacillus paraplantarum KM1 & 50 \\
\hline
\end{tabular}

\section{Fourier transform infrared spectroscopy (FTIR)}

Formation of silver nanoparticles was further confirmed, by analyzing the characteristic functional groups present in silver nanoparticles. FTIR spectrum is used to identify different functional groups, responsible for the reduction and stabilization of silver ions to silver nanoparticles. The FTIR spectrum of synthesized silver nanoparticles was presented in Fig 5 (a, b, c and d) respectively. L pentosus S6 synthesized silver nanoparticles (Fig 4a) shows absorbance peak at $1710 \mathrm{~cm}^{-1}$ which correspond to $\mathrm{C}=0$ stretching vibration of ketone. The absorbance peak at $2273 \mathrm{~cm}^{-1}$ corresponds to $\mathrm{N}=\mathrm{C}=\mathrm{O}$ stretching and presence of isocyanate functional group, whereas absorbance peak at $1367 \mathrm{~cm}^{-1}$ indicated C-O stretching vibration of an ester (Beekes et al. 2007). L. crustorum F11 synthesized silver nanoparticles (Fig 4b) shows absorbance peak at $3222 \mathrm{~cm}^{-1}$ referred to $\mathrm{O}-\mathrm{H}$ stretching and presence of carboxylic acid, whereas absorbance peak at $1628 \mathrm{~cm}^{-1}$ revealed $\mathrm{C}=\mathrm{C}$ stretch and the presence of alkene. The peak at $1146 \mathrm{~cm}^{-1}$ represents $\mathrm{O}-\mathrm{H}$ bond of the aliphatic ether, $1062 \mathrm{~cm}^{-1}$ corresponds to $\mathrm{O}-\mathrm{H}$ stretch of primary alcohol, 1925 $\mathrm{cm}^{-1}$ peak indicated $\mathrm{C}=\mathrm{C}=\mathrm{C}$ stretch of allene. For silver nanoparticles synthesized from $L$. plantarum $\mathrm{F} 22$ (Fig 4c) the absorbance peak at $1695 \mathrm{~cm}^{-1}$ corresponds to $\mathrm{C}=\mathrm{N}$ stretching of imine group. The absorbance peak at $1324 \mathrm{~cm}^{-1}$ could be attributed to $\mathrm{C}-\mathrm{N}$ bond of aromatic amide, and absorbance peak at $1635 \mathrm{~cm}^{-1}$ represented $\mathrm{C}=\mathrm{C}$ stretching of alkenes. Silver nanoparticles synthesized by $L$.

paraplantarum KM1 (Fig 4d) shows peak at $1695 \mathrm{~cm}^{-1}$ had C=0 stretch of conjugated aldehyde and peak at $1941 \mathrm{~cm}^{-1}$ was identified as $\mathrm{C}-\mathrm{H}$ stretch of aromatic compound. The peak at $2161 \mathrm{~cm}^{-1}$ represented S$\mathrm{C}=\mathrm{N}$ stretch of thiocyanate and $1647 \mathrm{~cm}^{-1}$ peak pointed out the $\mathrm{C}=\mathrm{N}$ stretch of sulfone (Fig. $5 \mathrm{~d}$ ). All the four probiotic isolates used in the study contain important functional groups (hydroxyl, protein, and carboxyl) in the cell membrane, which plays an important role in the reduction of silver nitrate and thus capable of biosynthesizing silver nanoparticles. Viorica et al., (2017) studied the FTIR spectrum of silver nanoparticles synthesized from Lactococcus lactis and observed absorption bands at $1650 \mathrm{~cm}^{-1}$ revealed the presence of amide, whereas amide II region ( $\mathrm{N}-\mathrm{H}$ bending and $\mathrm{C}-\mathrm{N}$ stretching) occurred at $1550 \mathrm{~cm}^{-}$ 1 . Milanowiski et al., (2017) observed peak at $1530-1630 \mathrm{~cm}^{-1}$ which could be attributed to amide II vibrations, for silver nanoparticles synthesized by L.casei.

\section{Antibacterial efficacy of silver nanoparticles}


The antimicrobial efficacy of synthesized AgNPs was assessed against challenging pathogens i.e., Staphylococcus aureus, Bacillus cereus and Listeria monocytogenes (Fig). All the four-probiotic synthesized AgNPs was found to exhibit strong antibacterial activity against the bacterial pathogens. However, out of all L. crustorum F11 synthesized AgNPs showed maximum zone of inhibition against all the microbial strains with maximum zone of inhibition of $200.61 \mathrm{~mm}$ against $S$. aureus, $141.01 \mathrm{~mm}$ for $L$. monocytogenes and 127.07 for B. cereus respectively (Fig. 5). However, Several Studies reported the antibacterial activity of lactic acid bacteria synthesized AgNP against different pathogens, while our study concluded the effectiveness of major probiotics against harmful challenging pathogens. Moodley et al. (2018) reported the antibacterial activity of silver nanoparticles against $K$. pneumoniae and $S$. aureus. Kumar et al. (2016) observed the antimicrobial efficacy of silver nanoparticles synthesized from Lactococcus amylophilus GV6 against $P$. aeruginosa MTCC 424, B. subtilis MTCC 121, S. aureus MTCC 96, E. coli MTCC 43 and Klebsiella pneumoniae MTCC 109 by using agar well plate assay and reported the zone of inhibition of $1.5 \mathrm{~cm}$ against $S$. aureus MTCC 96. Yusof et al. (2020) observed the antibacterial activity of biosynthesized silver nanoparticles from Lactobacillus plantarum TA4 against $S$. aureus, S. epidermidis, E. coli and Salmonella by agar well diffusion method.

\section{Antifungal activity of probiotics synthesized silver nanoparticles}

The antifungal activity of synthesized silver nanoparticles was assessed against three fungal pathogens viz. Pythium aphanidermatum, Fusarium oxysporum and Phytopthora parasitica. Here also, $L$.

crustorum F11 synthesized AgNP showed maximum inhibition against all the three fungal pathogens i.e., $23 \pm 0.37$ for $F$. oxysporum, $20 \pm 1$.01against $P$. parasitica and $32.6 \pm 0.48$ against $P$. aphanidermatum F11(Fig. 6). Matei et al. (2020) investigated the antifungal activity of silver nanoparticles synthesized by lactic acid bacteria against Aspergillus ochraceus, Penicillium expansum and Aspergillus flavus and observed maximum antifungal activity for Penicillium expansum (15.87 \pm 1.01$)$.

Although all the probiotic synthesized silver nanoparticles exhibited strong antimicrobial activity, but the one synthesized from $L$. crustorum F11 stands apart, as it showed the maximum antagonistic spectrum against different bacterial and fungal pathogens. This strong inhibitory effect could be attributed to its smaller size $(10 \mathrm{~nm})$ as compared to the other probiotic synthesized silver nanoparticles. Similar work is reported by Lu et al. (2013) where they examined size dependent antimicrobial activity of AgNPs against oral pathogenic bacteria. They observed that AgNPs having a size of $5 \mathrm{~nm}$ has a stronger antagonistic activity as compared to the one with size of 15 and $55 \mathrm{~nm}$ respectively. Morones et al. (2005) suggested that antimicrobial activity of silver nanoparticles was size dependent with higher antagonistic effect from nanoparticles whose size ranges from 1 10 nm. The small particle size helps AgNPs to adhere to the cell wall and penetrate the cell easily, which in turn enhances their antimicrobial activity against harmful pathogenic bacteria.

\section{Conclusions}


This study was carried out with the sole purpose to biosynthesize silver nanoparticles using health beneficial probiotic isolates and their antagonistic potential against challenging microbial strains. All of the four different in-house probiotic isolates used in this study were found to be safe and effective for the synthesis of silver nanoparticles. SEM analysis depicted the morphology and TEM analysis evaluated the size of different probiotic synthesized silver nanoparticles (20, 10 and 50nm). FTIR analysis identified different organic compound responsible for reduction and formation of silver nanoparticles. Furthermore, these biosynthesized silver nanoparticles revealed pronounced antimicrobial activity against different challenging bacterial and fungal pathogens. The results in our study recommend using probiotics, as a novel and ecofriendly tool for biosynthesizing silver nanoparticles, having effective antimicrobial activity and thus can be used against different health deteriorating multi drug resistant microorganisms.

\section{Declarations}

\section{Conflict of interest}

The authors declare that they have no conflict of interest

\section{Acknowledgment}

The authors thanks Mr. Arjun, Technician, Indian Institute of Technology, Mandi, Himachal Pradesh, India for technical support and help in obtaining TEM and FTIR results.

\section{Abbreviations}

SEM

Scanning Electron Microscope

TEM

Transmission Electron Microscope

FTIR

Fourier Transform Infrared Spectroscopy

AgNP

Silver Nanoparticles

$\mathrm{AgNO}_{3}$

Silver Nitrate

\section{References}

Arshad A (2017) Bacterial synthesis and applications of nanoparticles. Nano Sci Nano Technol 11(2):119. [Google Scholar]

Khatoon N, Alam H, Khan A (2019) Ampicillin Silver Nanoformulations against Multidrug resistant bacteria. Sci Rep 9:6848. https://doi.org/10.1038/s41598-019-43309-0 
Yusof HM, Rahman NA, Mohamad R, Zaidan UH (2020) Microbial Mediated Synthesis of Silver Nanoparticles by Lactobacillus plantarum TA4 and Its Antibacterial and Antioxidant Activity. Appl Sci 10(19):6973. https://doi.org/10.3390/app10196973

Hong L, Kin WS, Lee SM, Kang SK, Choi YJ, Cho CS (2019) Pullulan Nanoparticles as Prebiotics Enhance the Antibacterial Properties of Lactobacillus plantarum Through the Induction of Mild Stress in Probiotics. Front Microbio 10:1-12. https://doi.org/10.3389/fmicb.2019.00142

Gillor O, Etzion A, Riley MA (2008) The dual role of bacteriocins as anti- and probiotics. Appl Microbiol Biotechnol 81:591-606. https://doi.org/10.1007/s00253-008-1726-5

Boucher HW, Talbot GH, Bradley JS, Edwards JE, Gilbert D, Rice LB (2009) Bad bugs, no drugs: no ESKAPE! An update from the Infectious Diseases Society of America. Clin Infect Dis 48:1-12. https://doi.org/10.1086/595011

Peleg AY, Hooper DC (2010) Hospital-acquired infections due to gram-negative bacteria. N Engl J Med 362:1804-1813. https://doi.org/10.1056/nejmra0904124

Baptista PV, McCusker MP, Carvalho A, Ferreira DA, Mohan NM, Martins M, Fernandes AR (2018) NanoStrategies to Fight Multidrug Resistant Bacteria-"A Battle of the Titans". Front Microbiol 9:1-26. https://doi.org/10.3389/fmicb.2018.01441

Rajawat S, Qureshi MS (2012) Comparative study on bactericidal effect of silver nanoparticles, synthesized using green technology, in combination with antibiotics on Salmonella typhi. J Biomater Nanobiotechnol 3:480-485. https://doi.org/10.4236/JBNB.2012.34049

Muzammil S, Hayat S, Fakhar EAM, Aslam B, Siddique MH, Nisar MA (2018) Nanoantibiotics: future nanotechnologies to combat antibiotic resistance. Front Biosci 10:352-374. http://doi.org/10.2741/e827

Hemlata, Meena PR, Singh AP, Tejavath KK (2020) Biosynthesis of silver nanoparticles using Cucumis prophetarum aqueous leaf extract and their antibacterial and antiproliferative activity against cancer cell lines. ACS Omega 5(10):5520-5528. http://doi.org/10.1021/acsomega.0c00155

Lee NY, Ko WC, Hsueh PR (2019) Nanoparticles in the Treatment of Infections Caused by MultidrugResistant Organisms. Front Pharmacol 10(1153):1-9. http://doi.org/10.3389/fphar.2019.01153

Mosallam SF, Amer E, Diab RG (2014) Potentiated anti-microsporidial activity of Lactobacillus acidophilus $\mathrm{CH} 1$ bacteriocin using gold nanoparticles. Exp Parasitol 144:14-21. http://doi.org/10.1016/j.exppara.2014.06.002

Akhtar N, Pathak K (2017) Probiotics as a Tool to Biosynthesize Metallic Nanoparticles: Research Reports and Patents Survey. Recent Pat on Drug Del Form,11: 5-18. 10.2174/1872211311666170313124335 
Mikiciuk J, Mikiciuk E, Wronska A, Szterk A (2015) Antimicrobial potential of commercial silver nanoparticles and the characterization of their physical properties toward probiotic bacteria isolated from fermented milk products 51(4): 222-229. https://doi.org/10.1080/03601234.2015.1120614

Kalimathu K, Suresh Babu R, Venkataraman D, Bilal M, Gurunathan S (2008) Biosynthesis of silver nanocrystals by Bacillus licheniformis. Colloid Surf B Biointer 65:150-153.

http://doi.org/10.1016/j.colsurfb.2008.02.018

Garmasheva I, Kovalenko N, Voychuk S, Ostapchuk A, Livinska O, Oleschenko L (2016) Lactobacillus species mediated synthesis of silver nanoparticles and their antibacterial activity against opportunistic pathogens in vitro. Bioimpacts 6(4):219-223. http://doi.org/10.15171/bi.2016.29

Matei A, Matei S, Matei GM, Cogalniceanu G, Cornea CP (2020) Biosynthesis of silver nanoparticles mediated by culture filtrate of lactic acid bacteria, characterization and antifungal activity. EuroBiotech $\mathrm{J}$ 4:97-103. http://dx.doi.org/10.2478/ebtj-2020-0011

Berton V, Montesi F, Losasso C, Facco DR, Toffan A, Terregino C (2014) Study of the interaction between silver nanoparticles and Salmonella as revealed by transmission electron microscopy. J Prob Health 3:15. DOI:10.4172/2329-8901.1000123

Xiangqian L, Huizhong X, Zhe Sheng C, Guofang C (2011) Biosynthesis of Nanoparticles by Microorganisms and Their Applications. J of nanomat 11:1-16. https://doi.org/10.1155/2011/270974

Viorica RP, Pawel P, Kinga M, Michal Z, Katarzyna R, Boguslaw B (2017) Lactococcus lactis as a safe and inexpensive source of bioactive silver composites. Appl microbio biotechn 101(19):7141-7153.

https://doi.org/10.1007/s00253-017-8443-x

Haris P, Severcan F (1999) FTIR spectroscopic characterization of protein structure in aqueous and nonaqueous media. Journal of Molecular Catalysis B: Enzymatic 7:207-221. http://doi.org/10.1016/S13811177(99)00030-2

Prasad KS, Pathak D, Patel A, Dalwadi P, Prasad R, Patel P, Selvaraj K (2011) Biogenic synthesis of silver nanoparticles using Nicotiana tobaccum leaf extract and study of their antibacterial effect. Afr $\mathrm{J}$ of Biotechn 10(41):122-8130. https://doi.org/10.5897/AJB11.394

Lu Z, Rong K, Li J, Yang H, Chen R (2013) Size dependent antibacterial activities of silver nanoparticles against oral anaerobic pathogenic bacteria. J Mater Sci Mater Med. 2013 24(6):1465-1471. http://doi.org/10.1007/s10856-013-4894-5

Morones JR, Elechiguerra JL, Camacho A, Holt K, Kouri JB, Ramirez JT, Yacaman MJ (2005) The bactericidal effect of silver nanoparticles. Nanotechn 16(10):2346-2353. http://doi.org/10.1088/0957$4484 / 16 / 10 / 059$ 
Moodley JS, Krishna SBN, Pillay K, Sershen, Govender P (2018). Green synthesis of silver nanoparticles from Moringa oleifera leaf extracts and its antimicrobial potential. Adv Nat Sci Nanosci Nanotechnol 9(1): 1-9 Google Scholar

Kumar KK, Mahalakshmi S, Harikrishna N, Reddy G (2016) Production, characterization and antimicrobial activity of silver nanoparticles produced by Lactobacillus amylophilus GV6. E J OF Pharmaceut Med Res 3(7):236242

Sintubin L, De Windt W, Dick J, Mast J, Van Der Ha D, Verstraete W, Boon N (2009) Lactic acid bacteria as reducing and capping agent for the fast and efficient production of silver nanoparticles. Appl microbio biotechn 84(4):741-749. https://doi.org/10.1007/s00253-009-2032

Ranganath E, Rathod v, Banu A (2012) Screening of Lactobacillus spp. for mediating the biosynthesis of silver nanoparticles from silver nitrate. IOSR J of Pharm 2(2):237-241. http://dx.doi.org/10.9790/30130220237241

Dhoondia ZH, Chakraborty H (2012) Lactobacillus mediated synthesis of silver oxide nanoparticles 2(15): 1-7 https://doi.org/10.57722F55741

Sarvamangala D, Kondala K, Sivakumar N, Babu MS, Manga S (2013) Synthesis, characterization and antimicrobial studies of AgNPs using probiotics. Int Res J Pharm 4:240-243.

http://doi.org/10.7897/2230-8407.04352

Omidi B, Hashemi SJ, Bayat M, Larijani K (2014) Biosynthesis of silver nanoparticles by Lactobacillus fermentum. B of Environm Pharmaco and. L Sci 3(12):186-192 Google Scholar

Mew TW, Rosales AM (1986) Bacterization of rice plants for control of sheath blight caused by Rhizoctonia solani. Phytopath76: 1260-1264

Beekes M, Lasch P, Naumann D (2007) Analytical applications of Fourier transform-infrared (FTIR) spectroscopy in microbiology and prion research. Vet Microbiol 123(4):305-319. https://doi.org/10.1016/j.vetmic.2007.04.010

Milanowski M, Pomastowski P, Railean V, Rafinska K, Ligor T, Buszewski B (2017) Biosorption of silver cations onto Lactococcus lactis and Lactobacillus casei isolated from dairy products. PLoS ONE 12(3):e0174521. https://doi.org/10.1371/journal.pone.0174521

Naseer QA, Xue X, Wang X, Dang S, Din SU, kalsoom, Jamil J (2020) Synthesis of silver nanoparticles using Lactobacillus bulgaricus and assessment of their antibacterial potential. Braz $\mathrm{J}$ of Biol 84

https://doi.org/10.1590/1519-6984.232434

Kimura H, Sashihara T, Matsusaki H, Sonomoto K, Ishizaki A (1998) Novel bacteriocin of Pediococcus sp. ISK-1 isolated from well-aged bed of fermented rice bran. Ann N Y Acad Sci 13(864):345-3488. 


\section{Figures}

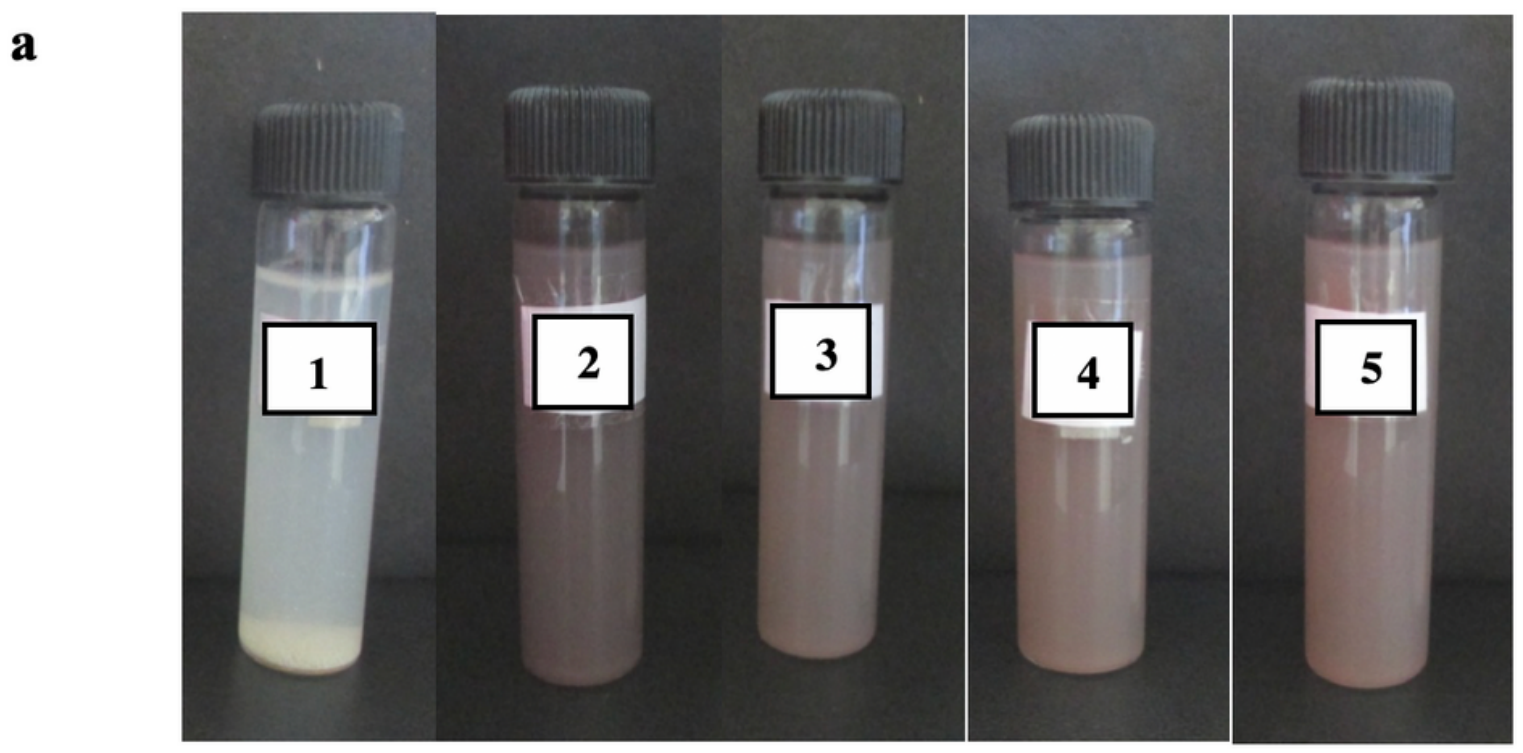

b

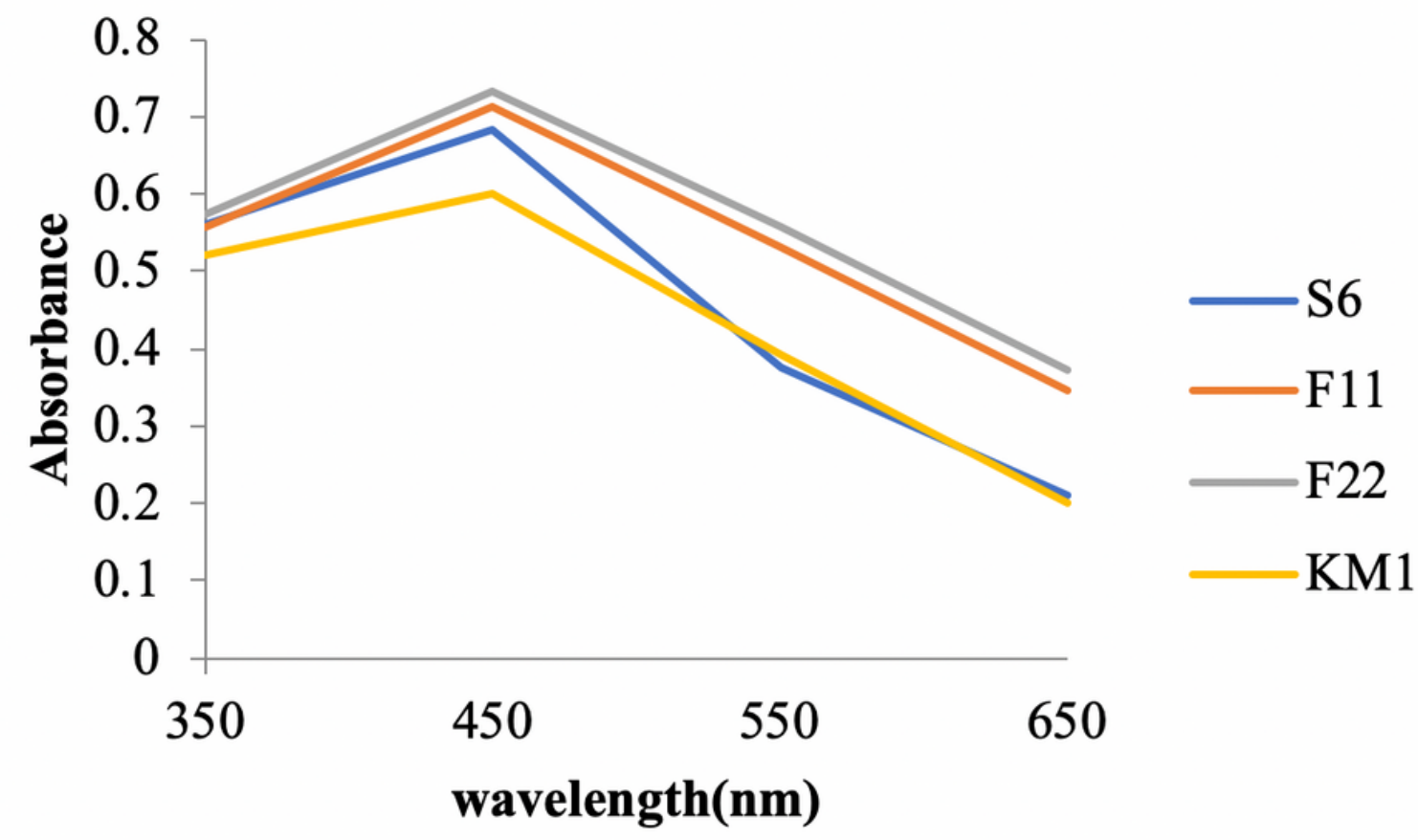

Figure 1

(a) Silver nanoparticles synthesized by four in-house probiotic isolates showing color change: (1) control (AgN03) (2) L. pentosus S6 AgNP (3) L. crustorum F11 AgNP (4) L. plantarum F22 AgNP (5) L. paraplantarum KM1 AgNP; (b) UV-Vis spectra of synthesized AgNPs at different wavelengths 


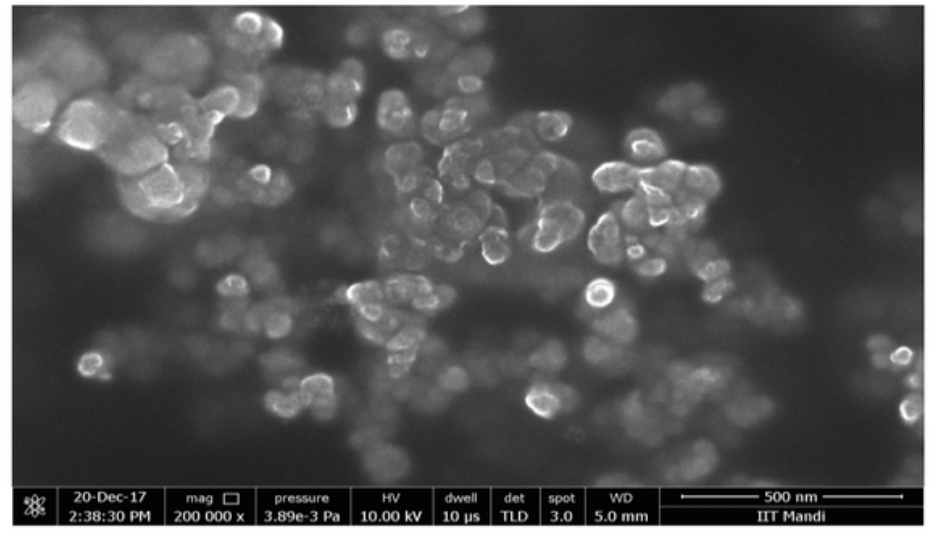

(a)

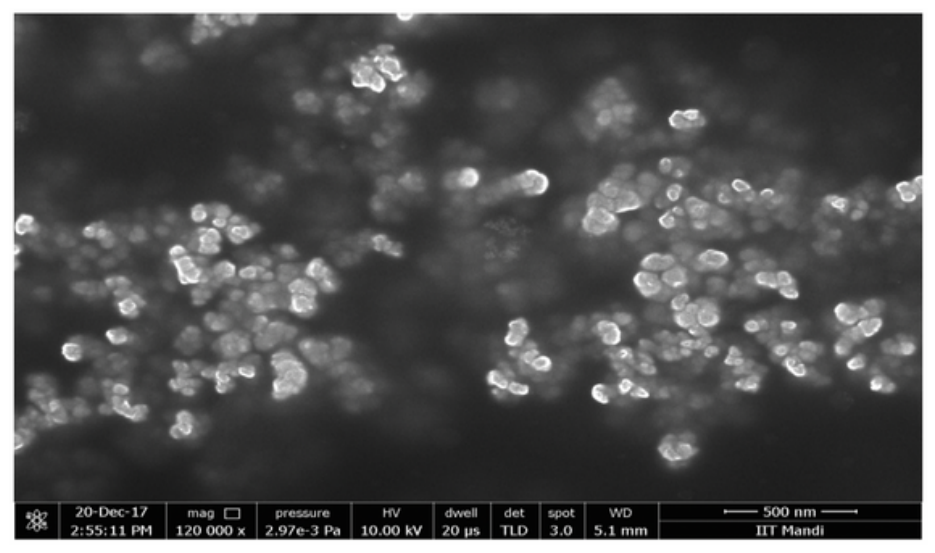

(c)

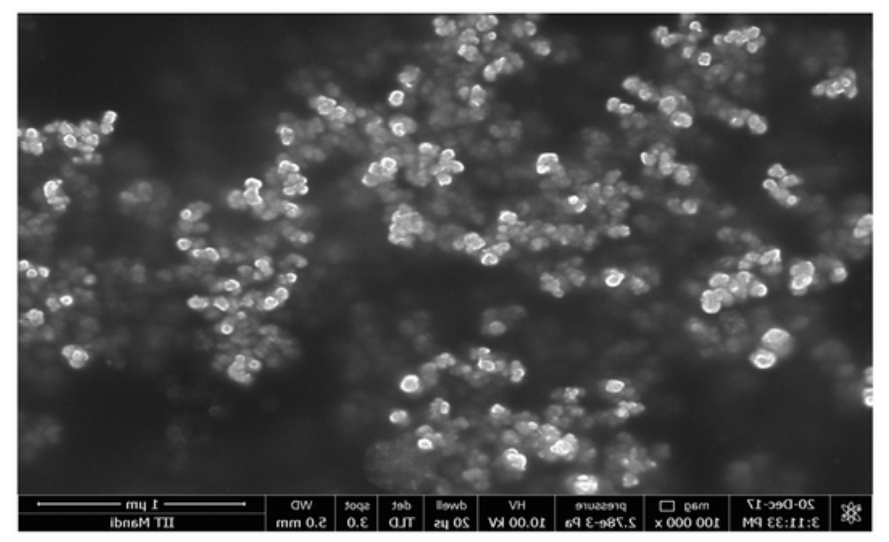

(b)

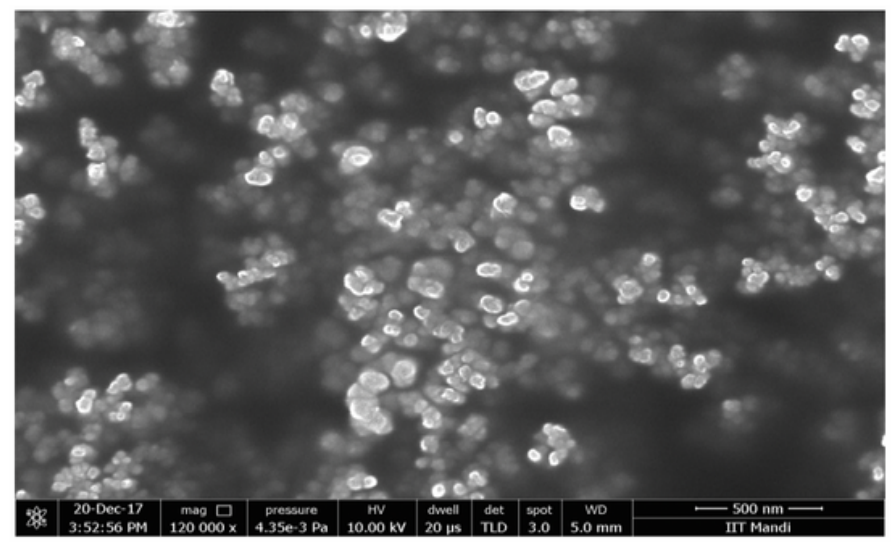

(d)

\section{Figure 2}

Scanning electron microscope (SEM) micrograph of silver nanoparticles synthesized by (a) L. pentosus S6, (b) L. crustorum F11 (c) L. plantarum F22 (d) L. paraplantarum KM1 


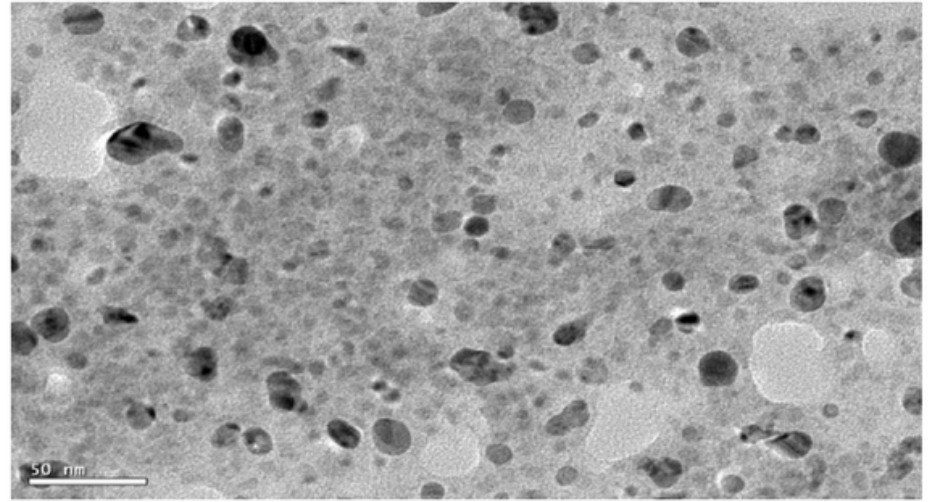

(a)

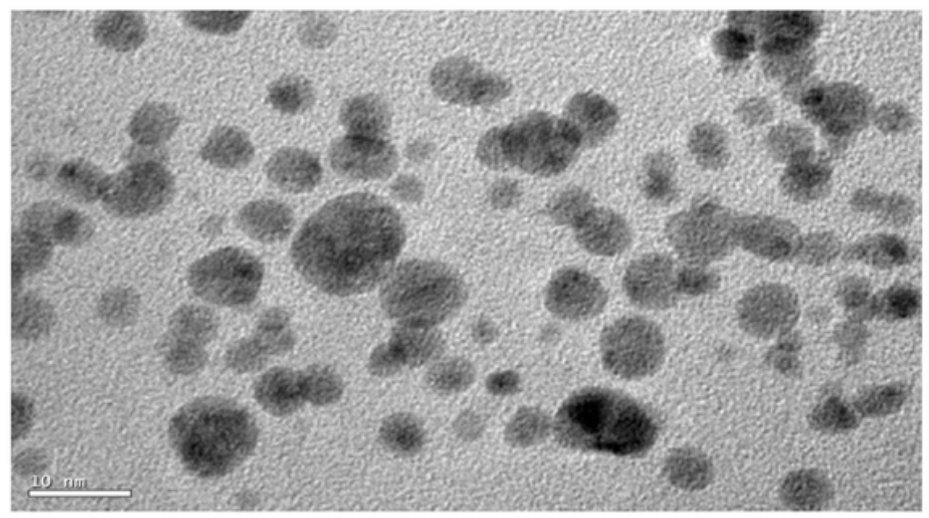

(c)

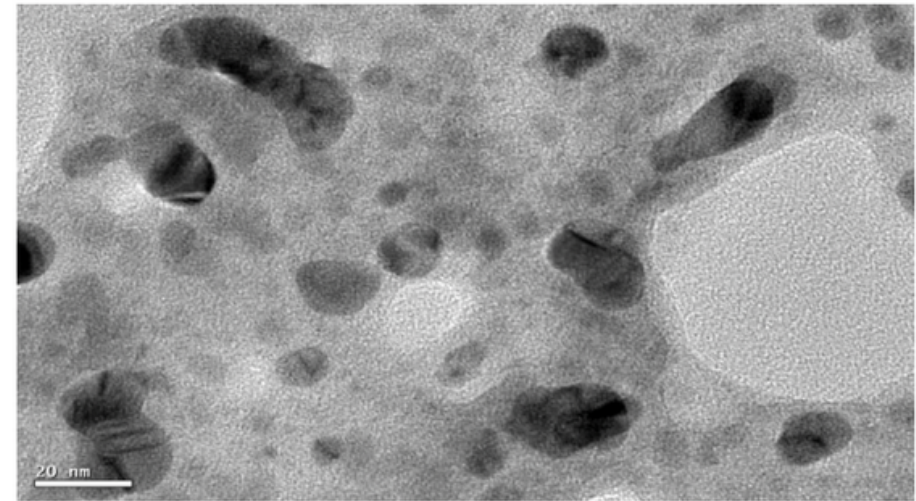

(b)

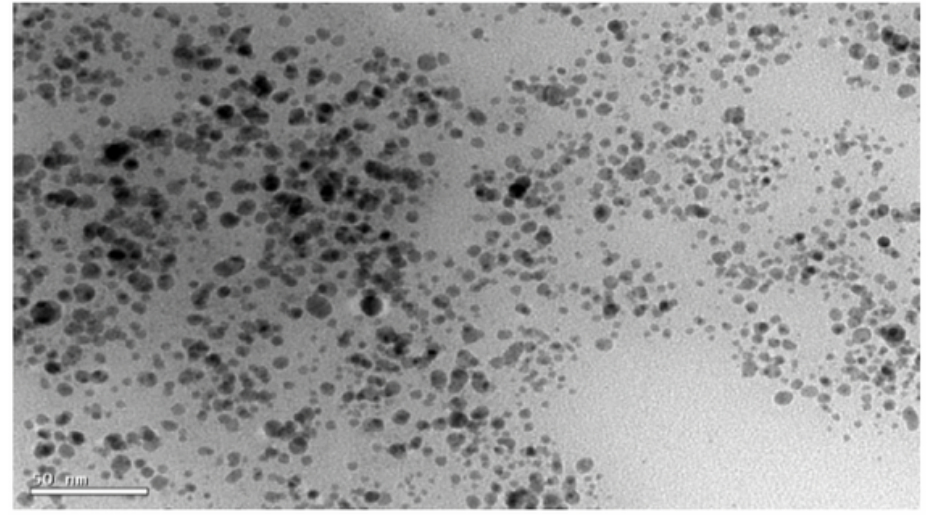

(d)

\section{Figure 3}

Transmission electron microscopy (TEM) micrograph of silver nanoparticles synthesized by (a) L. pentosus S6, (b) L. crustorum F11 (c) L. plantarum F22 (d) L. paraplantarum KM1 


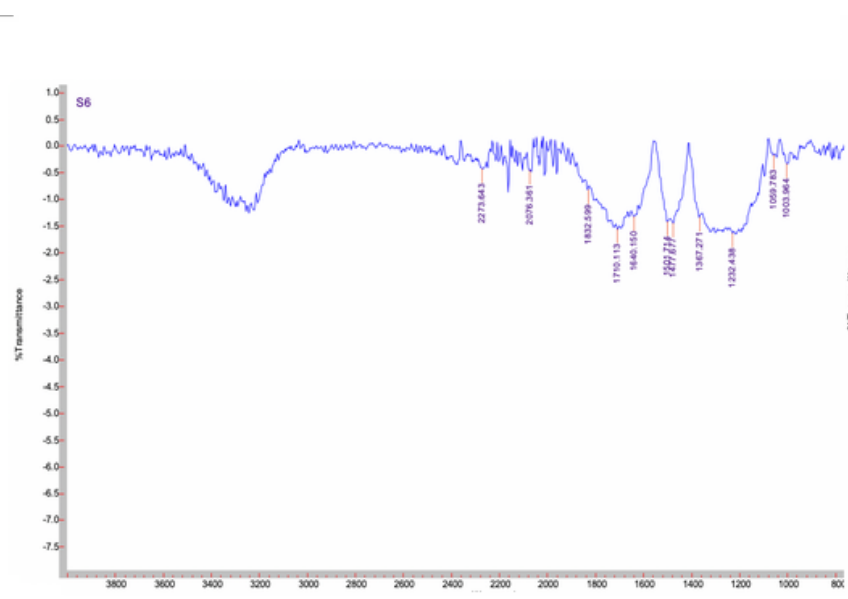

(a)

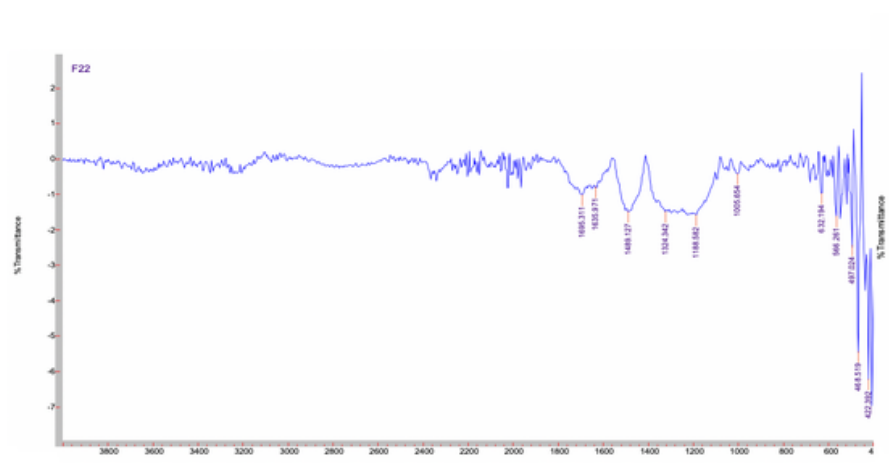

(c)

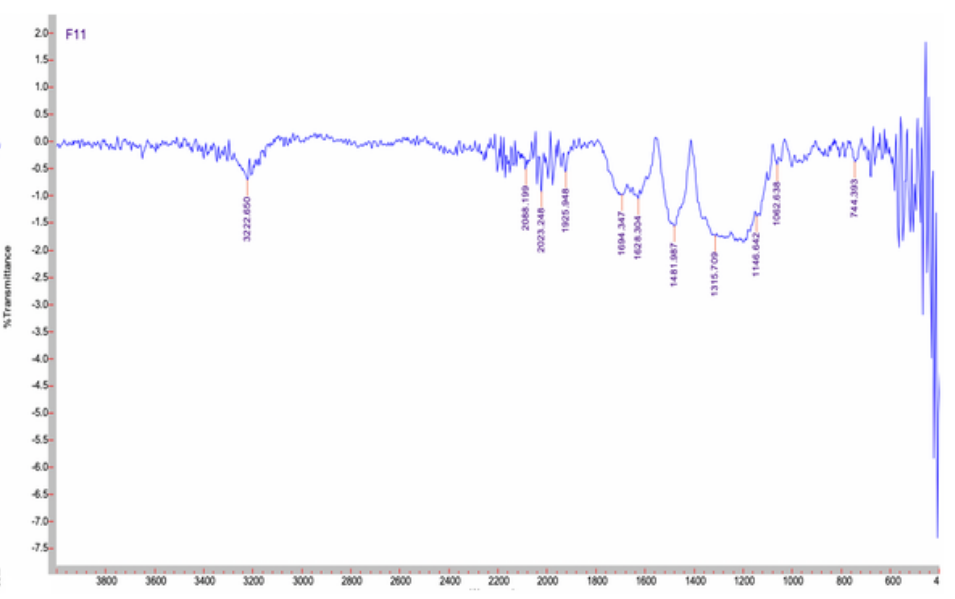

(b)

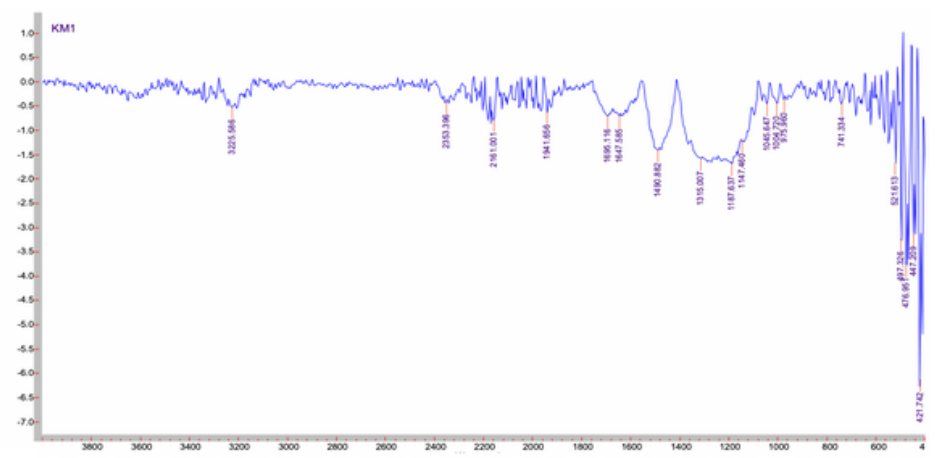

(d)

\section{Figure 4}

FTIR spectrum of silver nanoparticles synthesized by (a) L. pentosus S6, (b) L. crustorum F11 (c) L. plantarum F22 (d) L. paraplantarum KM1
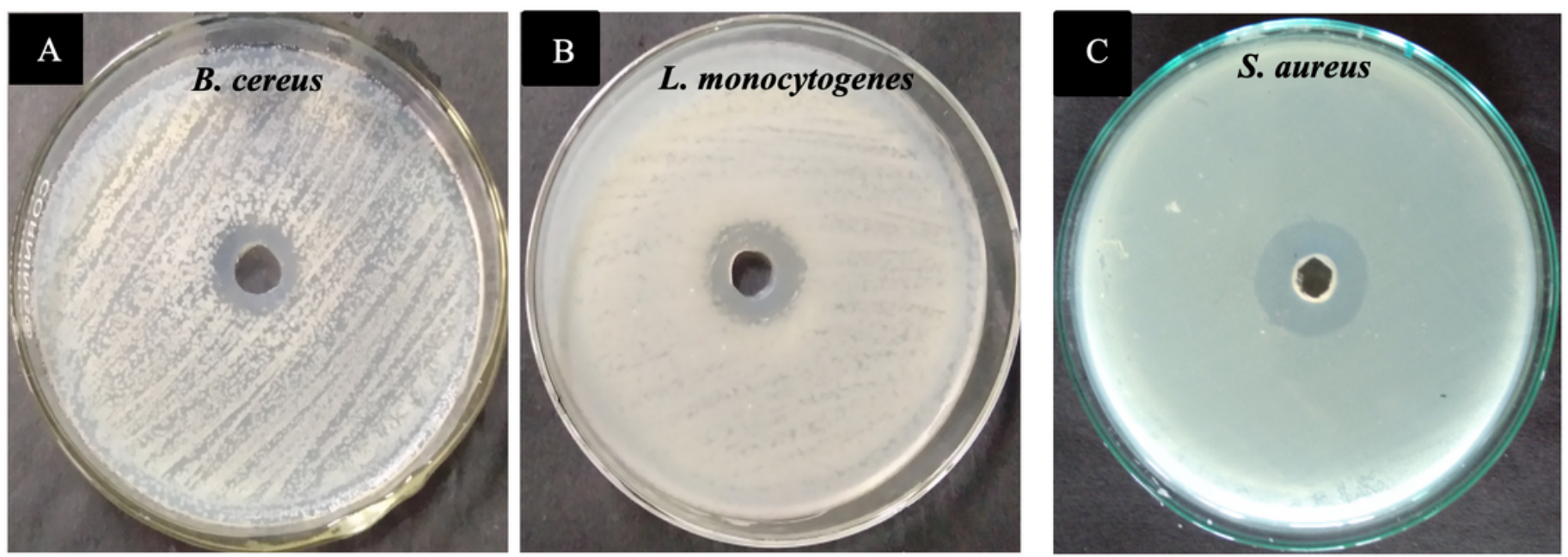

Figure 5 
Antibacterial activity of L. crustorum F11 synthesized silver nanoparticles against different bacterial pathogens

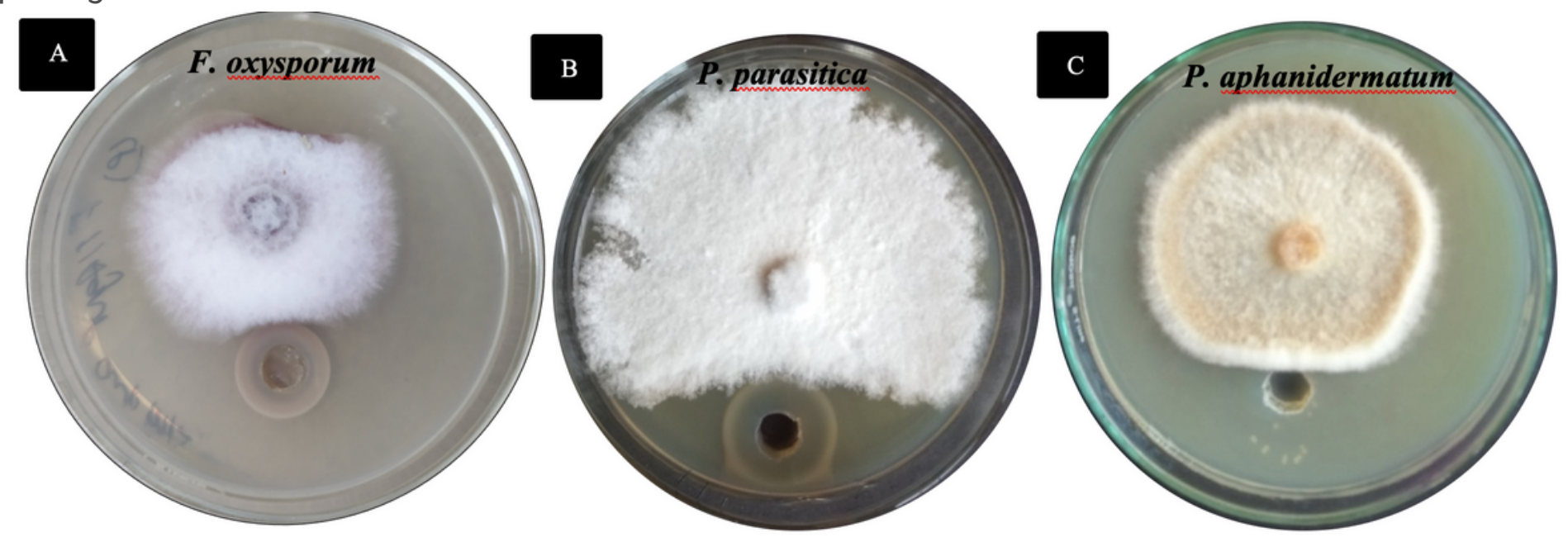

Figure 6

Antifungal activity of L. crustorum F11 synthesized silver nanoparticles against different fungal pathogens

\section{Supplementary Files}

This is a list of supplementary files associated with this preprint. Click to download.

- Doc1.docx

- $\mathrm{G}$ 